\title{
National Scientific Performance Evolution Patterns: Retrenchment, Successful Expansion, or Overextension ${ }^{1}$
}

Mike Thelwall, Jonathan M. Levitt

Statistical Cybermetrics Research Group, University of Wolverhampton, UK.

National governments would like to preside over an expanding and increasingly high impact science system but are these two goals largely independent or closely linked? This article investigates the relationship between changes in the share of the world's scientific output and changes in relative citation impact for 2.6 million articles from 26 fields in the 25 countries with the most Scopus-indexed journal articles from 1996 to 2015. There is a negative correlation between expansion and relative citation impact but their relationship varies. China, Spain, Australia, and Poland were successful overall across the 26 fields, expanding both their share of the world's output and its relative citation impact, whereas Japan, France, Sweden and Israel had decreased shares and relative citation impact. In contrast, the USA, UK, Germany, Italy, Russia, Netherlands, Switzerland, Finland, and Denmark all enjoyed increased relative citation impact despite a declining share of publications. Finally, India, South Korea, Brazil, Taiwan, and Turkey all experienced sustained expansion but a recent fall in relative citation impact. These results may partly reflect changes in the coverage of Scopus and the selection of fields.

\section{Introduction}

A key scientific goal of governments and research funders is to promote more and better research. Funding increases might widen the research base, producing more research, and/or deepen it by attracting successful researchers, paying for state-of-the-art equipment, or requiring less teaching. Policy makers may influence the relationship between quality and quantity by directly or indirectly rewarding one at the expense of the other (Butler, 2003; see also: Bloch \& Schneider, 2016; Dijstelbloem, Huisman, Miedema, \& Mijnhardt 2014). It would therefore be useful to know whether there tends to be a systematic relationship between research quality and quantity at the national level, irrespective of the financial or other causes.

Citation counts are sometimes used as indicators of scientific quality. Although the two correlate in most disciplines (HEFCE, 2015), citation impact differs from research quality because the latter can incorporate the commercial, societal or health benefits of research. Almost all studies that investigate research quality use scholarly impact as a proxy due to the lack of quality information. Whilst there is considerable research about the relationship between productivity and impact for individual scientists and research groups (e.g., Larivière \& Costas, 2016; Sandström \& van den Besselaar, 2016; de Solla Price, 1976; Merton, 1968), there is relatively little for entire countries. Other factors being equal, larger countries will produce more publications and have greater total scholarly impact (Aksnes, Schneider, \& Gunnarsson, 2012). The following additional cause-and-effect relationships seem likely to have some effect at the country level, most of which suggest that expansion will tend to cooccur with higher average citation impact.

\footnotetext{
${ }^{1}$ Thelwall, M. \& Levitt, J.M. (in press). National scientific performance evolution patterns: retrenchment, successful expansion, or overextension. Journal of the Association for Information Science and Technology.
} 
- Increased funding generates expansion and higher impact: An expanding economy may fund more higher education and raise standards through increased salary and resources. The opposite can also occur, as in the case of Russia (King, 2004).

- Increased impact generates expansion: A country that increases the average impact of its research may generate more publications by attracting more productive staff, more PhD students or more funding.

- Expansion increases citation impact: Expansion can increase citation impact by drawing in younger researchers, who tend to produce higher impact research (Gingras, Lariviere, Macaluso, \& Robitaille, 2008; cf. Stroebe, 2010). Expansion can also increase the average impact of papers as a side effect of the tendency for national self-citation (e.g., see: Lancho-Barrantes, Bote, Vicente, Rodríguez, \& de Moya Anegón, 2012; Thelwall \& Maflahi, 2015), especially in larger countries where the effect would be numerically bigger.

- Expansion lowers citation impact in Scopus/WoS: National expansion may lead citation indexes to cover more national journals from the expanding country, hence incorporating low impact journals and lowering the average impact of its publications (Jonathan Adams, personal communication).

- Policy decisions, competition and luck can alter the national quantity/impact balance: Policy makers may prioritise scholarly impact or quantity for political or economic reasons, such as by directing a nation's researchers to economic or wider social benefit goals, or by setting goals centring on citation impact. This may take the form of increased funding for strategically important research areas (Clark, 2009; Collins, Patel, Joestl, March, Insel, Daar, \& Glass, 2011). Luck may also play a role through the success of international competitors and collaborating nations (Gonzalez-Brambila, Reyes-Gonzalez, Veloso, \& Perez-Angón, 2016; Tahamtan, Afshar, \& Ahamdzadeh, 2016), as well as chance factors within a country (Simonton, 2004), such as major scientific breakthroughs or the emergence of individual prominent scientists (e.g., Cypriot economics Nobel laureate Christopher A. Pissarides).

Despite the above, there does not seem to be a simple relationship between system expansion and increasing citation impact (or vice versa), at least relative to world norms. A study of 11 large countries 2008-12 found a clear expansion/increasing relationship only for China, with no countries showing the opposite, five countries (UK, Japan, France, Germany) contracting but increasing citation impact (both relative to the world average), the USA contracting and maintaining its citation impact, and India expanding but reducing its citation impact (Elsevier, 2013: Figure 1.2, panel A). An analysis of science and engineering articles for the USA, European Union (EU), Japan, China and India between 2001 and 2012, found that all increased their relative citation impact but only India and China also increased their share of the World's publications (National Science Board, 2016, Figures 0-11, 0-12, 5-30). A similar EU-centred analysis 2004-2010 (EU, USA, China, Japan) found all except Japan to have increasing relative citation impact and all except Japan to have increasing absolute numbers of publications (percentages were not reported) (Science-Metrix, 2015, page 5). In contrast, the USA's share of the world's publications and top cited papers both decreased 1992-2003 (Leydesdorff \& Wagner, 2009).

The mixed findings above may be partly due to the expansion of science in China as well as India and Iran to some extent. China's share of the world's science papers and citations grew from 1994 to 2003, with the rate of citations per paper also increasing (from a visual inspection of figures 2 and 3 in: Zhou \& Leydesdorff, 2006). Although its social 
sciences growth has been modest in comparison (Zhou, Thijs, \& Glänzel, 2008), China's overall expansion means that other countries must increase their publication output more rapidly to expand their share of the world's publications.

\section{Research question}

Despite the research discussed above, which often covers short time periods, limited numbers of countries and focuses on other issues, no study has systematically investigated the relationship between citation impact and publication quantity at the national level. This paper uses data from 25 fields from 1996 to 2015 to compare national research impact with national research volume over twenty years to assess whether average research impact changes tend to associate with research volume changes. The objective is not to analyse trends in the countries themselves but to examine the data for evidence of an underlying research volume - research impact relationship.

- Do countries that increase their share of the world's research also tend to increase the average impact of this research, and vice versa?

\section{Methods}

Scopus was used as the data source because of its greater international coverage than the Web of Science (Li, Burnham, Lemley, \& Britton, 2010; López-Illescas, de Moya-Anegón \& Moed, 2008; Moed \& Visser, 2008), which is particularly useful for international comparisons. To be systematic, the seventh subject in each of the 26 broad Scopus categories was chosen. In broad Scopus categories with fewer than seven subjects, counting was conducted cyclically to find a replacement, ignoring miscellaneous categories. The last category with a 7 in was added from the huge medical broad category to give it better representation. The complementary therapy category was skipped to avoid an unrepresentative subject area. This systematic method was designed to give a wide range of different fields within science and social science, and a systematic method was used to reduce the risk of researcher bias in field selection. The category Dental Assisting was subsequently excluded since it had no articles for years before 2007, leaving $26^{2}$.

This sample of fields may introduce a bias because it may exclude fields in which a country excels or is particularly weak. All scientometric studies at the national level must sample because no database contains a comprehensive databases of research outputs and their citations. Similarly, studies that use the Web of Science rather than Scopus would have weaker international coverage. Nevertheless, the restriction to a specific set of fields, a practical data collection limitation, introduces an additional field sampling bias.

The year 1996 was chosen as the starting point due to the relative stabilisation of the size of the Scopus database by this year. The most recent complete year (2016) was excluded to ensure that all articles had at least a full year to attract citations, ensuring that none of the data was trivial. Although longer citation windows are preferred for research evaluations, this is less important for comparisons (but see the discussion).

\footnotetext{
${ }^{2}$ Applied Microbiology and Biotechnology; Atomic and Molecular Physics, and Optics; Cell Biology; Computer Vision and Pattern Recognition; Control and Systems Engineering; Dermatology; Discrete Mathematics and Combinatorics; Emergency Nursing; Endocrine and Autonomic Systems; Finance; Fluid Flow and Transfer Processes; Forestry; Fuel Technology; Geology; Health, Toxicology and Mutagenesis; History and Philosophy of Science; Human Factors and Ergonomics; Medical Laboratory Technology; Organizational Behavior and Human Resource Management; Pharmaceutical Science; Polymers and Plastics; Small Animals; Social Psychology; Spectroscopy; Statistics, Probability and Uncertainty; Transplantation
} 
Only documents of type Article were extracted from Scopus to focus on the core type of research output and to exclude documents that attracted a particularly high or low citation count compared to standard articles (e.g., reviews, editorials). When a field had more than 10000 articles in a single year, only the first 5000 and last 5000 articles were downloaded, giving a balanced set. The restriction to the first and last 5000 articles should not introduce biases because it seems unlikely that a country will tend to author articles in the early, middle or late part of the year. The limit to 10,000 articles per year reduces the importance of subject areas with large categories, which can cause a bias for countries that publish their highest or lowest impact work disproportionately in large categories but should affect comparisons over time within a country less. Article information was obtained from Scopus between 18 December 2016 and 17 January 2017.

Author nationalities were extracted from the Scopus address fields. These were not always complete and cases where the country affiliations did not match the author list were excluded. For the remaining documents, articles were attributed to countries using the fractional author counting scheme, which is better than full counting for national-level calculations (Aksnes, Schneider, \& Gunnarsson, 2012; Huang, Lin, \& Chen, 2011). If an article had $n$ authors and $k$ came from country $\mathrm{A}$, then $\mathrm{A}$ would be allocated a $k / n$ share of the article and its citations.

The average impact of articles from a country was estimated using the Mean Normalised Log Citation Score (MNLCS). For a single field and year, this is the arithmetic mean of the citation counts of the articles produced by the country, after adding 1 and taking the natural log; subsequently dividing by the world average for the same formula. Thus, if country $\mathrm{A}$ has $k_{i}$ out of the $n_{i}$ authors for article $i$ (where $k_{i}=0$ if $\mathrm{A}$ is not a coauthor) that has $c_{i}$ citations, and there are $N$ articles in a field and year, then

$$
M N L C S_{A}=\frac{\frac{1}{\sum_{i=1}^{N} \frac{k_{i}}{n_{i}}} \sum_{i=1}^{N} \frac{k_{i}}{n_{i}} \ln \left(1+c_{i}\right)}{\frac{1}{N} \sum_{i=1}^{N} \ln \left(1+c_{i}\right)}
$$

For multiple fields and years, the above calculation is used except that the citation counts are normalised separately for each field and year (Thelwall, 2017ab).

MNLCS was chosen in preference to the standard Mean Normalised Citation Score (MNCS) indicator (Waltman, van Eck, van Leeuwen, Visser, \& van Raan, 2011ab) because the latter is more influenced by individual highly cited articles, which might obscure any underlying trends. The geometric mean could also have been used for the calculations (Fairclough \& Thelwall, 2015) but would not have easily shown the relationship to the world average citation rates.

It is not useful to compare the overall output of a country with its average impact because the output is influenced by the productivity and size of a country. For example, Russia and China produce large volumes of research primarily because they are large countries, irrespective of the efficiency of their research (see also: Siddiqi, Stoppani, Anadon, \& Narayanamurti, 2016). Thus, relational tests were used to assess whether expansion in a research system associates with increased average impact. This focus on expansion largely nullifies the influence of country size on the results, although population growth differs to some extent between countries (UNPFA, 2016, p.101-4).

Correlations between the share of the world's outputs in a field (percentage of articles authored) and the average impact of research in the field (MNLCS) were used as the primary quantitative mechanism. If countries have tended to either grow or shrink in national share of publications over the period, then a positive correlation between the two 
would indicate that higher productivity associated with higher average research impact. Since there may be substantial policy changes during the 20 years, a follow-up qualitative analysis was also conducted to identify overall patterns from the shapes of the article share and average impact graphs. Pearson correlations were used rather than Spearman correlations because the data was not highly skewed.

The analysis is restricted to the 25 countries with the largest cumulative number of articles in the period 1996-2015. The choice of 25 is a practical limitation to make the results presentable. Including a cut-off also reduces the risk that the findings are obscured by including countries with too few articles to reliably reflect underlying national changes in each field.

\section{Results}

The results show a slight overall tendency (median Pearson correlation of -0.13 ) amongst the 25 most productive countries for size (share of the world's populations) to negatively correlate with impact (relative to the world average: MNLCS) 1996 to 2015 (Table 1). Thus, as a country's share of the world's publications increases, its (MNLCS) citation impact is likely to slightly decrease, and vice versa. The magnitude of the correlation tends to reduce as an offset is introduced to account for any delay between increases in research capacity and increases in average research impact (negative numbers in Table 1), or the opposite (positive numbers in Table 1). From this it seems that any delayed relationships in either direction are unlikely to be strong.

Some examples here illustrate the meaning of the average correlations in Table 1.

- The value -0.32 for an offset of 0 for the USA in Table 1 is the average of the 26 Pearson correlations between MNLCS and proportions of articles authored in each field. For example, the first of the 26 correlates the USA's share of Applied Microbiology and Biotechnology articles from each of 1996 to 2015 with the USA's MNLCS for the same years (i.e., $\mathrm{n}=20$ for the correlation).

- The value -0.15 for an offset of 1 for the USA in Table 1 is the average of the 26 Pearson correlations between MNLCS and proportions of articles authored in each field. The first of the 26 correlates the USA's share of Applied Microbiology and Biotechnology articles from each of 1997 to 2015 with the USA's MNLCS for 1996 to 2014 (i.e., $\mathrm{n}=19$ for the correlation). Each year proportion is paired with the MNLCS from the year before.

- The value -0.20 for an offset of -1 for the USA in Table 1 is the average of the 26 Pearson correlations between MNLCS and proportions of articles authored in each field. The first of the 26 correlates the USA's share of Applied Microbiology and Biotechnology articles from each of 1996 to 2014 with the USA's MNLCS for 1997 to 2015 (i.e., $n=19$ for the correlation). Each year proportion is paired with the MNLCS from the year after. 
Table 1. Average Pearson correlations between proportion of articles in the set and MNLCS for articles from 1996 to 2015 in 26 fields ( $n=15$ to $n=20$ for each correlation, n=26 for the average). Offsets are in years, with negative offsets indicating that article proportions are correlated with MNLCS values in later years.

\begin{tabular}{|c|c|c|c|c|c|c|c|c|c|c|c|}
\hline Offset* & -5 & -4 & -3 & -2 & -1 & 0 & 1 & 2 & 3 & 4 & 5 \\
\hline USA & -0.05 & -0.02 & -0.12 & -0.17 & -0.20 & -0.32 & -0.15 & -0.10 & -0.02 & 0.00 & 0.01 \\
\hline China & 0.32 & 0.33 & 0.33 & 0.34 & 0.30 & 0.32 & 0.35 & 0.39 & 0.40 & 0.46 & 0.44 \\
\hline Japan & 0.03 & 0.05 & 0.05 & 0.03 & 0.06 & -0.07 & 0.08 & 0.05 & 0.04 & 0.03 & 0.08 \\
\hline UK & -0.02 & -0.05 & -0.14 & -0.15 & -0.24 & -0.26 & -0.20 & -0.17 & -0.16 & -0.19 & -0.15 \\
\hline Germany & -0.14 & -0.16 & -0.19 & -0.21 & -0.17 & -0.26 & -0.18 & -0.07 & -0.09 & -0.02 & 0.01 \\
\hline India & -0.14 & -0.14 & -0.18 & -0.22 & -0.28 & -0.25 & -0.22 & -0.13 & -0.01 & 0.07 & 0.08 \\
\hline France & -0.14 & -0.20 & -0.25 & -0.24 & -0.32 & -0.43 & -0.29 & -0.25 & -0.23 & -0.14 & -0.10 \\
\hline Canada & -0.07 & -0.07 & -0.15 & -0.08 & -0.15 & -0.21 & -0.09 & -0.06 & -0.05 & 0.00 & 0.02 \\
\hline Italy & -0.08 & -0.08 & -0.17 & -0.16 & -0.19 & -0.31 & -0.21 & -0.15 & -0.12 & -0.10 & -0.06 \\
\hline South Korea & -0.05 & -0.11 & -0.05 & -0.03 & -0.07 & -0.09 & -0.05 & 0.04 & 0.08 & 0.06 & 0.12 \\
\hline Spain & -0.05 & -0.05 & -0.03 & -0.08 & -0.12 & -0.22 & -0.08 & -0.02 & 0.04 & 0.11 & 0.12 \\
\hline Russia & -0.04 & -0.11 & -0.17 & -0.24 & -0.31 & -0.31 & -0.24 & -0.17 & -0.19 & -0.14 & -0.07 \\
\hline Australia & 0.00 & 0.00 & -0.04 & -0.09 & -0.14 & -0.25 & -0.12 & -0.05 & -0.04 & -0.02 & -0.07 \\
\hline Brazil & -0.23 & -0.18 & -0.12 & -0.11 & -0.12 & -0.13 & -0.05 & -0.01 & 0.03 & 0.00 & 0.03 \\
\hline Taiwan & -0.08 & 0.00 & -0.03 & -0.05 & -0.02 & -0.03 & -0.05 & 0.07 & 0.10 & 0.09 & 0.12 \\
\hline Netherlands & -0.03 & -0.07 & -0.14 & -0.15 & -0.12 & -0.22 & -0.15 & -0.08 & -0.08 & 0.03 & 0.04 \\
\hline Poland & -0.02 & -0.03 & -0.01 & -0.01 & 0.01 & -0.02 & 0.03 & 0.02 & 0.04 & 0.05 & 0.12 \\
\hline Turkey & -0.12 & -0.08 & -0.06 & -0.06 & -0.01 & 0.06 & 0.11 & 0.10 & 0.17 & 0.16 & 0.21 \\
\hline Sweden & -0.08 & -0.09 & -0.04 & 0.00 & -0.08 & -0.02 & 0.00 & -0.02 & 0.02 & 0.01 & 0.00 \\
\hline Iran & -0.14 & -0.09 & -0.06 & 0.00 & 0.03 & 0.10 & 0.09 & 0.15 & 0.16 & 0.20 & 0.22 \\
\hline Switzerland & 0.01 & 0.05 & -0.02 & -0.01 & -0.01 & -0.08 & -0.02 & 0.02 & 0.02 & 0.01 & 0.03 \\
\hline Belgium & 0.06 & -0.02 & -0.03 & -0.04 & -0.09 & -0.23 & -0.08 & -0.12 & -0.11 & 0.00 & -0.02 \\
\hline Israel & 0.10 & 0.08 & -0.02 & -0.02 & -0.03 & 0.04 & -0.01 & 0.03 & 0.01 & -0.02 & -0.03 \\
\hline Finland & 0.09 & -0.03 & 0.01 & -0.05 & -0.08 & -0.11 & -0.12 & -0.01 & -0.05 & 0.02 & 0.08 \\
\hline Denmark & 0.00 & -0.06 & -0.07 & -0.05 & -0.04 & -0.02 & 0.02 & 0.06 & 0.07 & 0.04 & 0.09 \\
\hline Median & -0.05 & -0.06 & -0.06 & -0.06 & -0.09 & -0.13 & -0.08 & -0.02 & 0.01 & 0.01 & 0.03 \\
\hline
\end{tabular}

*Countries are in decreasing order of total publications analysed.

A correlation test only reveals the overall trend 1996-2015 but a more detailed analysis shows some common patterns in the relationship between the share of articles and MNLCS values (Table 2). Several rapidly expanding national science systems experienced an increasing share of the world's outputs and increasing impact relative to the world average (successful expansion in Table 2; Figure 1), albeit from a low baseline in the latter case. Spain modernised its research system during this period and increased its investment (Jiménez-Contreras, de Moya Anegón, \& López-Cózar, 2003), explaining its inclusion within this group. A few countries contracted overall, with a decreasing share of the world's publications and decreasing relative impact (unsuccessful retraction in Table 2; Figure 2). In between these extremes, many nations with stable advanced economies experienced a decreasing share of the world's scientific output but increasing relative impact (the successful retraction pattern in Table 2; see Figure 3).

Some developing nations with an expanding share of the world's publications were not always successful in their expansion, following one of two patterns. Their average 
impact either increased initially and then later reduced (unsuccessful expansion-a; Figure 4) or was initially constant before reducing (unsuccessful expansion-b; Figure 5). A complete set of graphs of all 25 countries is available in the online appendix (https://figshare.com/s/933fb5f4c87d8b26e367).

The national pattern is not necessarily followed for all fields within a country. For example, within the USA, although most fields follow the same broad pattern as the whole nation, a few do not (e.g., Spectroscopy - see online supplement for graph). A complete set of graphs of all countries and fields separately is available in the online appendix (25X26=650 different graphs: https://figshare.com/s/933fb5f4c87d8b26e367).

Most countries increased their MNLCS values (Table 2), which is counterintuitive since this calculation is normalised against the world average. This is possible because many countries with above average MNLCS values reduced their share of the world's articles. 
Table 2. Patterns in the relationship between share of the world's articles and relative impact (the correlation column echoes the 0 column of Table 1 , for convenience). The article and MNLCS columns record whether these values tend to increase $(+)$, decrease $(-)$, stay the same $(=)$ or follow another trend $(\sim)$ during 1996-2015. SR (successful retraction): Fewer articles, higher impact; SE (successful expansion): More articles, higher impact; UEa (unsuccessful expansion-a): More articles, initially increased impact, then lower impact; UR (unsuccessful retraction): fewer articles, lower impact; UEb (unsuccessful expansion-b): More articles, initially constant impact, then lower impact.

\begin{tabular}{|l|r|r|l|l|l|}
\hline Country & $\begin{array}{r}\text { Articles } \\
\text { authored } \\
\mathbf{1 9 9 6 - 2 0 1 5}\end{array}$ & Correlation & $\begin{array}{l}\text { Articles } \\
\text { trend }\end{array}$ & $\begin{array}{l}\text { MNLCS } \\
\text { trend }\end{array}$ & Pattern \\
\hline USA & 538191 & -0.32 & - & + & SR \\
\hline China & 360779 & 0.32 & + & + & SE \\
\hline Japan & 144449 & -0.07 & - & - & UR \\
\hline UK & 121657 & -0.26 & - & + & SR \\
\hline Germany & 118452 & -0.26 & - & + & SR \\
\hline India & 94459 & -0.25 & + & $\sim$ & UEb \\
\hline France & 94005 & -0.43 & - & - & UR \\
\hline Canada & 77534 & -0.21 & - & $=$ & \\
\hline Italy & 72456 & -0.32 & - & + & SR \\
\hline South Korea & 68105 & -0.09 & + & $\sim$ & UEa \\
\hline Spain & 65253 & -0.22 & + & + & SE \\
\hline Russia & 57625 & -0.31 & - & + & SR \\
\hline Australia & 52190 & -0.25 & + & + & SE \\
\hline Brazil & 40676 & -0.13 & + & $\sim$ & UEb \\
\hline Taiwan & 40252 & -0.03 & + & $\sim$ & UEb \\
\hline Netherlands & 36773 & -0.22 & - & + & SR \\
\hline Poland & 33686 & -0.02 & + & + & SE \\
\hline Turkey & 31760 & 0.06 & + & $\sim$ & UEa \\
\hline Sweden & 26272 & -0.02 & - & - & UR \\
\hline Iran & 25724 & 0.10 & + & $\sim$ & \\
\hline Switzerland & 22163 & -0.08 & - & + & SR \\
\hline Belgium & 21275 & -0.23 & - & + & SR \\
\hline Israel & 16868 & 0.04 & - & - & UR \\
\hline Finland & 15469 & -0.11 & - & + & SR \\
\hline Denmark & 14070 & -0.02 & - & + & SR \\
\hline Total & 2605096 & & & & \\
\hline & & & & & \\
\hline
\end{tabular}




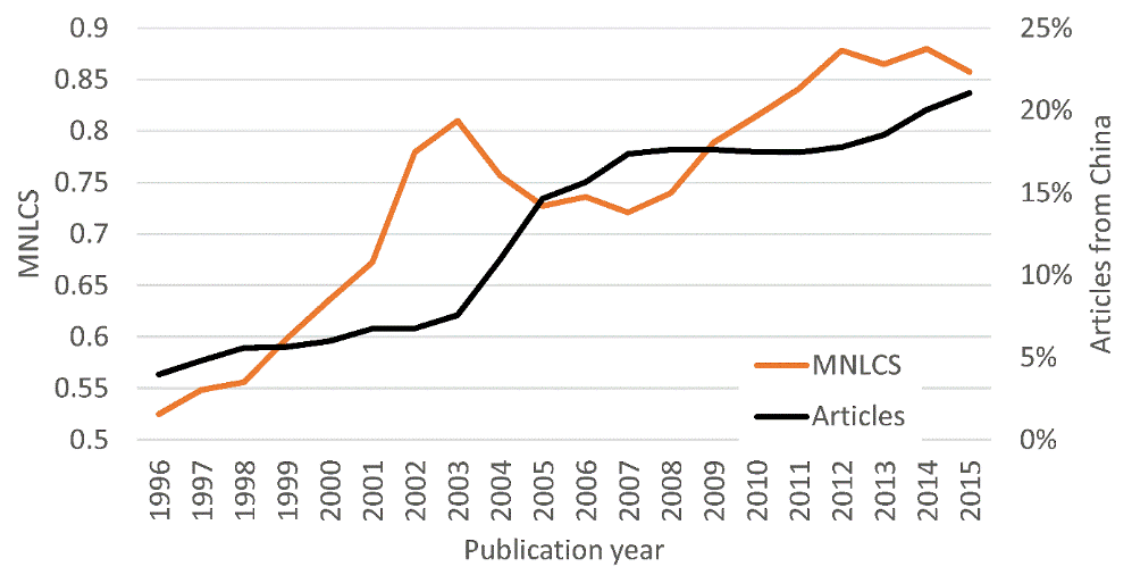

Figure 1. The share of the articles in the data set and the median MNLCS value by year for China. The MNLCS scale shows the full range of values to emphasise relative changes although this visually exaggerates absolute changes. This illustrates the successful expansion pattern in Table 2 (increasing share of articles, increasing relative impact).

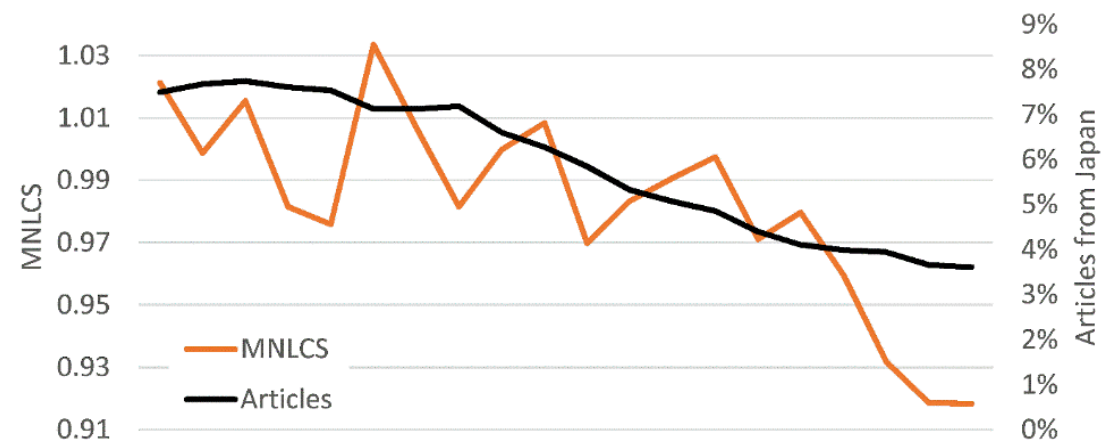

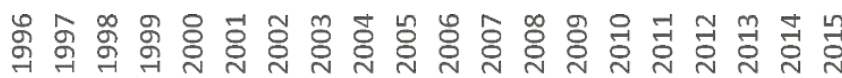

Publication year

Figure 2. As Figure 1 for Japan, illustrating unsuccessful retraction (decreasing share of articles, decreasing relative impact).

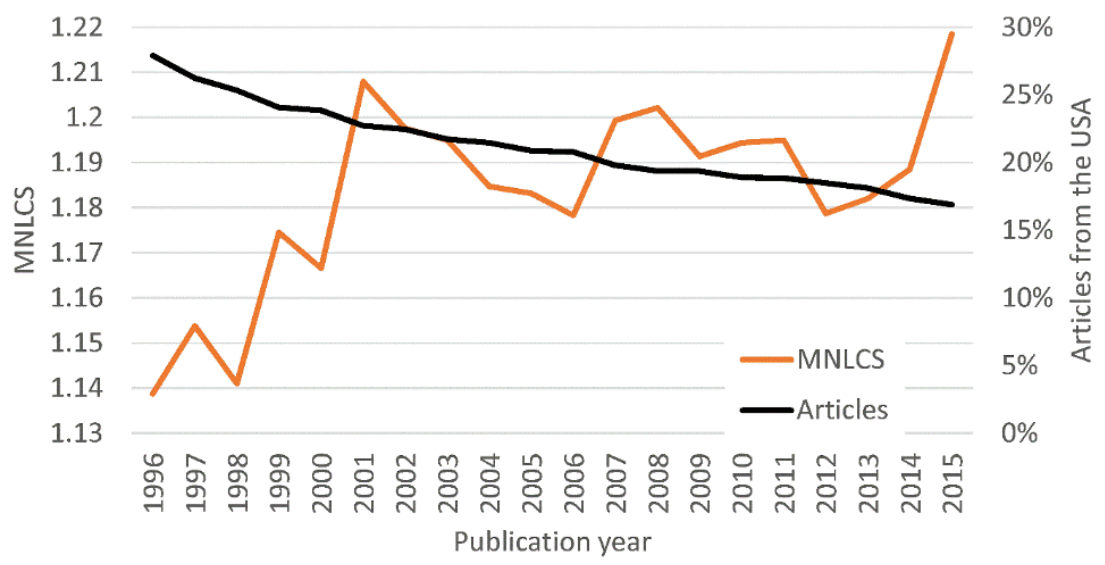

Figure 3. As Figure 1 for the USA, illustrating successful retraction (decreasing share of articles, increasing relative impact). 


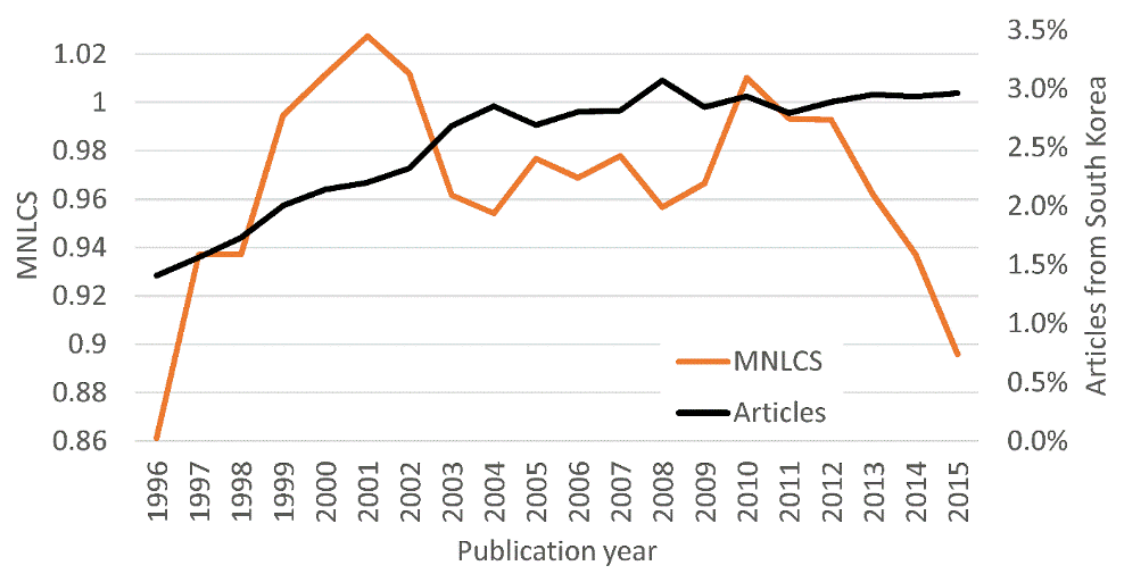

Figure 4. As Figure 1 for South Korea, illustrating unsuccessful expansion-a (more articles, initially increased impact, then lower impact).

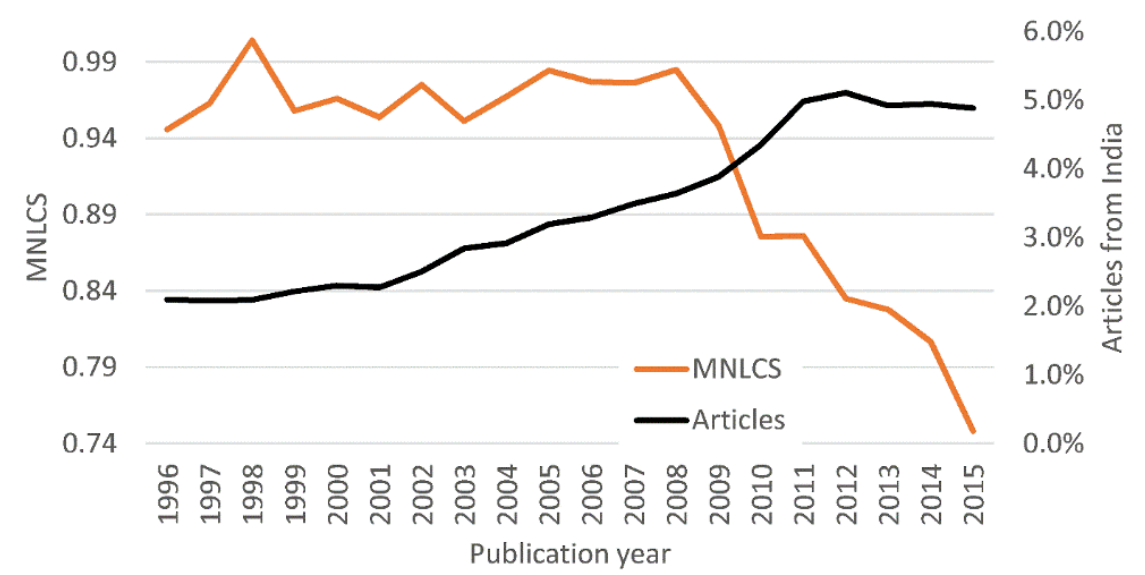

Figure 5. As Figure 1 for India, illustrating unsuccessful expansion-b (more articles, initially constant impact, then lower impact).

\section{Discussion and limitations}

A limitation of the findings is that they are partly dependant on the fields selected and countries have differing rates of success in individual fields (Albarrán, Crespo, Ortuño, \& Ruiz-Castillo, 2010). Moreover, the period chosen affects the shapes of the graphs produced. They are also dependant on the method of counting articles and the coverage of the Scopus database. To check for this, the total number of articles authored by each country in each year 1996-2015 was obtained from both Scopus and WoS and compared with the paper data (see graphs A1-A10 at: https://figshare.com/s/933fb5f4c87d8b26e367). All three sources showed broadly similar but not identical shapes for all countries. The paper data had higher percentages of articles from India and China. This was probably due to the use of fractional counting for this paper, whilst the web interface data from WoS and Scopus uses whole author counting. This can make a difference for China and India because of their high proportion of articles without international collaboration. Database coverage issues were also evident to some extent. The most noticeable example was the increase in the percentage of Chinese-authored papers in Scopus 2003-2005. Whilst WoS Chinese-authored papers increased from $5.2 \%$ to $7.1 \%$, those from Scopus nearly doubled from $6.6 \%$ to $12.4 \%$ and the paper data for the 26 fields also nearly doubled from $9.3 \%$ to $17.2 \%$.

The results can be affected by high impact, highly internationally co-authored articles, especially for smaller countries (Albarrán, Perianes-Rodríguez, \& Ruiz-Castillo, 2015), but this factor should be reduced using the MNLCS indicator and fractional citation 
counting. The Scopus categorisation scheme might also affect the results because it classifies by journal rather than by article (Waltman \& van Eck, 2012) and might therefore be misleading if any country tends to publish in multidisciplinary journals within a given field. The findings may not apply to countries with historically smaller science systems, which may follow different publication, collaboration and productivity logics (Siddiqi, Stoppani, Anadon, \& Narayanamurti, 2016). A particularly important exception is Saudi Arabia, with a rapidly growing publication output.

A fundamental problem with the analysis is that it is internal to science and does not consider the differing contributions of researchers to economic prosperity or other societal benefits (Cimini, Gabrielli, \& Labini, 2014). It is entirely possible that a nation has decreasing average impact research because its scholars are devoting an increasing proportion of their time to consultancy or nationally beneficial research topics (e.g., Basalla, 1967). This is supported by evidence of relationships between research and industry varying by country. There are substantial international differences in the level of business investment in research as a percentage of GDP (OECD, 2017: Table 24), with the USA, Sweden, South Korea, Japan, Israel, Germany, Finland and Austria having relatively high values (above $1.9 \%$ in 2015) and Russia, Spain, Poland, Italy having low values (below $1 \%$ in 2015).

The temporal pattern for each country is affected by an important factor outside of its control: international competition. The rapid growth of China ensures that other countries must increase their publication output substantially to retain their existing share of the world's publications. This problem is exacerbated by the growth of other countries, such as India and Brazil. Thus, whilst this paper analyses the relationship between output share and relative citation impact, even a moderate decline in output share may represent a substantial increase in output in absolute terms. To partly check for this, the calculations were repeated after removing China and the results were similar (see the online appendix). Although it would be possible to remove all increasing countries, such as India, Iran and Brazil, before repeating the analysis, this would not be realistic because competition is an inherent part of the system.

The results are influenced by the coverage of Scopus. The set of journals included in its database is periodically reviewed and its coverage of journals from one country can increase or decrease relative to the world average. To test for this, the proportion of articles indexed in Scopus in journals with a name containing "Journal" or "Proceedings" that also contained a country demonym (e.g., American) was counted for 1996 and 2015 and the difference divided by the former. Thus, the result for each country is $\left(\frac{c_{2015}}{w_{2015}}-\frac{c_{1996}}{w_{1996}}\right) / \frac{c_{1996}}{w_{1996}}$, where

- $w_{n}$ : the number of hits for the Scopus query SRCTITLE(journal) OR SRCTITLE(proceedings) in year $n$

- $c_{n}$ : the number of hits for the Scopus query (SRCTITLE(journal) OR SRCTITLE(proceedings)) AND SRCTITLE(c) in year $n$, where $c$ is the country demonym.

The terms Journal and Proceedings were chosen as two common terms used in national journals (e.g., Journal of the British Archaeological Association; Proceedings of the American Mathematical Society). The use of such terms ensures that non-academic magazines indexed by Scopus are excluded from the calculation (e.g., Thelwall, 2016). This is an approximation because some countries tend to name journals entirely in national languages (e.g., Revue Francaise de Psychanalyse), use an international demonym (e.g., Scandinavian, European) or avoid demonyms in journal names to avoid connotations of research that is not internationally relevant (e.g., probably the UK case). Moreover, a minority of Chinese journals (containing $17 \%$ of the number of articles captured above, in contrast to only $3 \%$ 
for Canada compared to Canadian, for example) use the country name instead of its demonym (e.g., China Journal of Social Work). Percentages calculated in this way should not be compared between countries, but it is reasonable to analyse differences within a country over time.

The successful and unsuccessful retraction patterns usually associate with a decreasing share of national journals whereas successful and unsuccessful expansion usually associate with the opposite (Table 3). Thus, for example, the expansion of China is partly due to the expansion in coverage of Chinese journals by Scopus, although this in turn is itself probably due to the expansion in the production of Chinese journals. Expansion in the coverage of nationally-focused journals also has the effect of reducing the national citation impact because the new journals are likely to be lower impact (otherwise they would have been previously indexed). It is therefore possible that this process would lead to a successbreeds-(technical)-failure mechanism as a country producing increasing amounts of increasingly high impact research experiences a decrease in average citation impact in citation databases that expand their coverage by adding low impact journals from the successful nation. This may account for the cases of apparent overexpansion (unsuccessful expansion-a/b). This can also lead to an increase in MNLCS values for other countries, due to a lowering of the world average. Longer citation lag times for developing nations can also give them relatively low citation rates for recently published articles (Jonathan Adams, personal communication).

\section{Conclusions}

From the results, there is not a simple relationship between an expanding research system and increasing average research impact, at least relative to world norms. Thus, the answer to the research question is negative. Nevertheless, four countries broadly followed the successful expansion pattern (China, Spain, Australia, Poland), although only one (China) had an overall positive Pearson correlation between publication share and average citation impact. In contrast, nine countries managed to increase their relative citation impact despite a decreasing share of the world's outputs, a pattern of retrenchment (USA, UK, Germany, Italy, Netherlands, Russia, Switzerland, Finland, Belgium, Denmark). These have widely differing levels of national expenditure on research and development (R\&D) as a percentage of GDP, with the USA (2.79\%) being above the OECD average (2.40\%) and Russia far below (1.13\%) (OECD, 2017: Table 2). The same is true for higher education R\&D spending as percentage of GDP, with Denmark (0.99\%) being far above the OECD average (0.43\%) and Russia far below (0.11\%) (OECD, 2017: Table 44). Thus, the pattern is not the direct result of the level of R\&D spending.

Perhaps most worryingly, two countries have shrinking shares of the world's research in the 26 fields at the same time as their average relative impact is decreasing (Japan, France). Although this could be an artefact of database coverage issues, this seems unlikely in the case that could be tested, Japan (i.e., the discussion around Table 3). Alternatively, it is possible that one or both countries specialise in areas not covered by the sample of 26 fields or focus on applications of research in their own countries.

Ominously, five countries appeared to be overextending their research system expansion, with relative impact per paper falling in recent years (India, South Korea, Brazil, Taiwan, Turkey). This recent fall could be due to technical issues (discussed above) or policy changes towards education or research applications, however.

The main policy implication of the finding is that governments should not assume that financing and prioritising either research productivity or research impact will naturally 
lead to the expansion of both. Whilst this is possible in developing nations, from the developed nations analysed, only Spain and Switzerland experienced this double increase. For developed nations, increasing the relative impact of research is a reasonable goal, whereas maintaining research share is also achievable, but difficult.

In terms of future research, it would be useful to examine the overexpansion pattern in more detail. It may reflect countries prioritising quantity over quality or scholarly impact, for example due to the need for a rapidly expanding higher education system for an expanding high technology sector of the economy, but other explanations are also possible.

Additional data, graphs and calculations are at:

https://figshare.com/s/933fb5f4c87d8b26e367.

\section{References}

Aksnes, D.W., Schneider, J.W., \& Gunnarsson, M. (2012). Ranking national research systems by citation indicators. A comparative analysis using whole and fractionalised counting methods. Journal of Informetrics, 6(1), 36-43.

Albarrán, P., Crespo, J.A., Ortuño, I., \& Ruiz-Castillo, J. (2010). A comparison of the scientific performance of the U.S. and the European Union at the turn of the $21^{\text {st }}$ century. Scientometrics, 85(1), 329-344.

Albarrán, P., Perianes-Rodríguez, A., \& Ruiz-Castillo, J. (2015). Differences in citation impact across countries. Journal of the Association for Information Science and Technology, $66(3), 512-525$.

Basalla, G. (1967). The spread of western science. Science, 156(3775), 611-622.

Bloch, C., \& Schneider, J. W. (2016). Performance-based funding models and researcher behavior: An analysis of the influence of the Norwegian Publication Indicator at the individual level. Research Evaluation, 25(4), 371-382.

Butler, L. (2003). Explaining Australia's increased share of ISI publications - the effects of a funding formula based on publication counts. Research Policy, 32(1), 143-155.

Cimini, G., Gabrielli, A., \& Labini, F. S. (2014). The scientific competitiveness of nations. PLoS ONE, 9(12), e113470.

Clark, J. H. (2009). Chemistry goes green. Nature Chemistry, 1(1), 12-13.

Collins, P. Y., Patel, V., Joestl, S. S., March, D., Insel, T. R., Daar, A. S., \& Glass, R. I. (2011). Grand challenges in global mental health. Nature, 475(7354), 27-30.

de Solla Price, D. (1976). A general theory of bibliometric and other cumulative advantage processes. Journal of the American Society for Information Science, 27(5), 292-306.

Dijstelbloem, H., Huisman, F., Miedema, F., \& Mijnhardt, W. (2014). Science in Transition status report. http://www.scienceintransition.nl/wpcontent/uploads/2014/07/Science-in-Transition-Status-Report-June-2014.pdf

Elsevier (2013). International Comparative Performance of the UK Research Base - 2013. https://www.gov.uk/government/publications/performance-of-the-uk-research-baseinternational-comparison-2013

Fairclough, R., \& Thelwall, M. (2015). More precise methods for national research citation impact comparisons. Journal of Informetrics, 9(4), 895-906. doi:10.1016/j.joi.2015.09.005

Gingras, Y., Lariviere, V., Macaluso, B., \& Robitaille, J. P. (2008). The effects of aging on researchers' publication and citation patterns. PloS ONE, 3(12), e4048.

Gonzalez-Brambila, C. N., Reyes-Gonzalez, L., Veloso, F., \& Perez-Angón, M. A. (2016). The scientific impact of developing nations. PloS ONE, 11(3), e0151328. 
HEFCE (2015). The Metric Tide: Correlation analysis of REF2014 scores and metrics (Supplementary Report II to the Independent Review of the Role of Metrics in Research Assessment and Management). HEFCE. DOI: 10.13140/RG.2.1.3362.4162

Huang, M.H., Lin, C.S., \& Chen, D.Z. (2011). Counting methods, country rank changes, and counting inflation in the assessment of national research productivity and impact. Journal of the American Society for Information Science and Technology, 62(12), 2427-2436.

Jiménez-Contreras, E., de Moya Anegón, F., \& López-Cózar, E. D. (2003). The evolution of research activity in Spain: The impact of the National Commission for the Evaluation of Research Activity (CNEAI). Research policy, 32(1), 123-142.

King, D. A. (2004). The scientific impact of nations. Nature, 430(6997), 311-316.

Lancho-Barrantes, B. S., Bote, G., Vicente, P., Rodríguez, Z. C., \& de Moya Anegón, F. (2012). Citation flows in the zones of influence of scientific collaborations. Journal of the American Society for Information Science and Technology, 63(3), 481-489.

Leydesdorff, L., \& Wagner, C. (2009). Is the United States losing ground in science? A global perspective on the world science system. Scientometrics, 78(1), 23-36.

Li, J., Burnham, J.F., Lemley, T., \& Britton, R.M. (2010). Citation analysis: Comparison of Web of Science, Scopus, SciFinder, and Google Scholar. Journal of Electronic Resources in Medical Libraries, 7(3), 196-217.

Larivière, V., \& Costas, R. (2016). How many is too many? On the relationship between research productivity and impact. PloS ONE, 11(9), e0162709.

López-Illescas, C., de Moya-Anegón, F., \& Moed, H. F. (2008). Coverage and citation impact of oncological journals in the Web of Science and Scopus. Journal of Informetrics, 2(4), 304-316.

Merton, R. K. (1968). The Matthew effect in science. Science, 159(3810), 56-63.

Moed, H. F., \& Visser, M. S. (2008). Appraisal of citation data sources. Centre for Science and Technology Studies, Leiden University. http://www.hefce.ac.uk/media/hefce/content/pubs/indirreports/2008/missing/Appra isal\%20of\%20Citation\%20Data\%20Sources.pdf.

National Science Board (2016). Science and Engineering Indicators 2016. Arlington, VA: National Science Foundation (NSB-2016-1).

OECD (2017). Main Science and Technology Indicators, Volume 2016 Issue 2, OECD Publishing, Paris. doi:10.1787/msti-v2016-2-en

Sandström, U., \& van den Besselaar, P. (2016). Quantity and/or quality? The importance of publishing many papers. PloS one, 11(11), e0166149.

Science-Metrix (2015). Analysis of bibliometric indicators for European policies 2000-2013. Brussels, Belgium: European Commission. https://ec.europa.eu/research/innovationunion/pdf/bibliometric_indicators_for_european_policies.pdf

Siddiqi, A., Stoppani, J., Anadon, L. D., \& Narayanamurti, V. (2016). Scientific wealth in Middle East and North Africa: Productivity, indigeneity, and specialty in 1981-2013. PloS ONE, 11(11), e0164500.

Simonton, D. K. (2004). Creativity in science: Chance, logic, genius, and zeitgeist. Cambridge, UK: Cambridge University Press.

Stroebe, W. (2010). The graying of academia: Will it reduce scientific productivity? American Psychologist, 65(7), 660-673.

Tahamtan, I., Afshar, A. S., \& Ahamdzadeh, K. (2016). Factors affecting number of citations: a comprehensive review of the literature. Scientometrics, 107(3), 1195-1225. 
Thelwall, M. \& Maflahi, N. (2015). Are scholarly articles disproportionately read in their own country? An analysis of Mendeley readers. Journal of the Association for Information Science and Technology, 66(6), 1124-1135.

Thelwall, M. (2016). Are there too many uncited articles? Zero inflated variants of the discretised lognormal and hooked power law distributions. Journal of Informetrics, 10(2), 622-633. doi:10.1016/j.joi.2016.04.014

Thelwall, M. (2017a). Three practical field normalised alternative indicator formulae for research evaluation. Journal of Informetrics, 11(1), 128-151. 10.1016/j.joi.2016.12.002

Thelwall, M. (2017b). Web indicators for research evaluation: A practical guide. San Rafael, CA: Morgan \& Claypool.

UNPFA (2016). State of World 2016. http://www.unfpa.org/sites/default/files/pubpdf/The_State_of_World_Population_2016_-_English.pdf

Waltman, L., van Eck, N. J., van Leeuwen, T. N., Visser, M. S., \& van Raan, A. F. (2011a). Towards a new crown indicator: Some theoretical considerations. Journal of Informetrics, 5(1), 37-47.

Waltman, L., van Eck, N. J., van Leeuwen, T. N., Visser, M. S., \& van Raan, A. F. (2011b). Towards a new crown indicator: An empirical analysis. Scientometrics, 87(3), 467-481.

Waltman, L., \& van Eck, N. J. (2012). A new methodology for constructing a publicationlevel classification system of science. Journal of the American Society for Information Science and Technology, 63(12), 2378-2392.

Zhou, P., \& Leydesdorff, L. (2006). The emergence of China as a leading nation in science. Research policy, 35(1), 83-104.

Zhou, P., Thijs, B., \& Glänzel, W. (2008). Is China also becoming a giant in social sciences? Scientometrics, 79(3), 593-621. 


\section{Appendix}

Table 3. Percentage of Scopus-indexed articles published in a journal name containing either "Journal" or "Proceedings" and the country demonym, as a proportion of all Scopus-indexed articles published in a journal with a name containing either "Journal" or "Proceedings" (irrespective of whether a country demonym was also present in the journal name). See online appendix for raw data and graphs for the full period 1996-2015. Patterns are repeated from Table 2 for convenience.

\begin{tabular}{|l|r|r|r|l|}
\hline Country & $\mathbf{1 9 9 6}$ & $\mathbf{2 0 1 5}$ & Increase & Pattern \\
\hline USA & $7.95 \%$ & $4.38 \%$ & $-45 \%$ & SR \\
\hline China & $1.34 \%$ & $3.10 \%$ & $71 \%$ & SE \\
\hline Japan & $2.40 \%$ & $0.70 \%$ & $-76 \%$ & UR \\
\hline UK & $2.73 \%$ & $1.03 \%$ & $-59 \%$ & SR \\
\hline Germany & $0.02 \%$ & $0.05 \%$ & $53 \%$ & SR \\
\hline India & $1.21 \%$ & $1.31 \%$ & $13 \%$ & UEb \\
\hline France & $0.00 \%$ & $0.00 \%$ & NA & UR \\
\hline Canada & $1.43 \%$ & $0.70 \%$ & $-58 \%$ & \\
\hline Italy & $0.10 \%$ & $0.09 \%$ & $-21 \%$ & SR \\
\hline South Korea & $0.22 \%$ & $0.51 \%$ & $103 \%$ & UEa \\
\hline Spain & $0.00 \%$ & $0.04 \%$ & NA & SE \\
\hline Russia & $0.88 \%$ & $0.41 \%$ & $-55 \%$ & SR \\
\hline Australia & $0.76 \%$ & $0.37 \%$ & $-56 \%$ & SE \\
\hline Brazil & $0.15 \%$ & $0.26 \%$ & $83 \%$ & UEb \\
\hline Taiwan & $0.00 \%$ & $0.03 \%$ & NA & UEb \\
\hline Netherlands & $0.00 \%$ & $0.00 \%$ & NA & SR \\
\hline Poland & $0.12 \%$ & $0.10 \%$ & $-8 \%$ & SE \\
\hline Turkey & $0.22 \%$ & $0.30 \%$ & $45 \%$ & UEa \\
\hline Sweden & $0.01 \%$ & $0.00 \%$ & $-82 \%$ & UR \\
\hline Iran & $0.02 \%$ & $0.37 \%$ & $1694 \%$ & \\
\hline Switzerland & $0.01 \%$ & $0.01 \%$ & $113 \%$ & SR \\
\hline Belgium & $0.01 \%$ & $0.00 \%$ & $-76 \%$ & SR \\
\hline Israel & $0.01 \%$ & $0.01 \%$ & $13 \%$ & UR \\
\hline Finland & $0.01 \%$ & $0.00 \%$ & $-100 \%$ & SR \\
\hline Denmark & $0.00 \%$ & $0.02 \%$ & NA & SR \\
\hline Scandinavian & $0.51 \%$ & $0.23 \%$ & $-46 \%$ & - \\
\hline & & & & \\
\hline
\end{tabular}

